\title{
Spectrophotometric assays for total antioxidant capacity (TAC) in dog serum: an update
}

\author{
Camila Peres Rubio1', Josefa Hernández-Ruiz², Silvia Martinez-Subiela'1, Asta Tvarijonaviciute ${ }^{1,3}$ \\ and José Joaquin Ceron ${ }^{1 *}$
}

\begin{abstract}
The aim of this review is to study the main spectrophotometric methods used to evaluate total antioxidant capacity (TAC) in serum samples of dogs. Total antioxidant capacity (TAC) is an analyte frequently used to assess the antioxidant status of biological samples and can evaluate the antioxidant response against the free radicals produced in a given disease. Trolox equivalent antioxidant capacity (TEAC), ferric reducing ability of plasma (FRAP), and cupric reducing antioxidant capacity (CUPRAC) are different assays described to determine TAC of a sample. This review explains the basis of each assay and their application in the determination of TAC in dogs, and also provides selected information about reports in humans for comparative purposes. It is concluded that, ideally, various different assays integrated in a panel should be used for TAC evaluation, since depending on the assay performed TAC results can be markedly different.
\end{abstract}

Keywords: Antioxidant activity, Canine serum, Human serum, Cupric, Ferric, Oxidative stress, Trolox

\section{Background}

An antioxidant is defined as "any substance that, when presented at low concentration compared to those of an oxidizable substrate (proteins, lipids, carbohydrates, and DNA), significantly delays, or prevents oxidation of that substrate" [1,2]. The main function of antioxidants is to protect the body against the destructive effects of free radicals damage [3].

Free radicals may be generated in cells and tissues from internal (such as inflammation, diseases or metabolism) or external sources (irradiation, pollution, food, drugs), or as a consequence of decreased protective capacity [1]. In any case, an increase in free radicals production can originate oxidative damage $[4,5]$.

\section{General concepts}

Total antioxidant capacity (TAC) is the measure of the amount of free radicals scavenged by a test solution [4],

\footnotetext{
* Correspondence: jjceron@um.es

${ }^{1}$ Interdisciplinary Laboratory of Clinical Analysis Interlab-UMU, Faculty of Veterinary Medicine, Regional Campus of International Excellence 'Campus Mare Nostrum', University of Murcia, 30100 Espinardo, Murcia, Spain Full list of author information is available at the end of the article
}

being used to evaluate the antioxidant capacity of biological samples $[3,6,7]$.

\section{Classification of different TAC assays}

Assays to measure TAC can be direct, which are based on the ability to inhibit the oxidation of a substance. One of the most commonly used direct assays is the Trolox (6-hydroxy-2,5,7,8-tetramethylchroman-2-carboxylic acid) equivalent antioxidant capacity (TEAC) with modifications mainly based on period of time used for measurement, and radical formed [8-10]. The oxygen radical absorbance capacity (ORAC) assay is another direct assay described [11]. On the other hand, there are indirect assays, such as the ferric reducing ability of plasma (FRAP) [12], and the cupric reducing antioxidant capacity (CUPRAC) [13], which are based on determination of the ability of a sample to reduce a metal complex [6]. Trolox equivalent antioxidant capacity (TEAC), FRAP and CUPRAC are spectrophotometric, whereas ORAC is a fluorometric assay.

On the basis of the chemical reactions involved, TAC assays can be also divided into two categories: hydrogen atom transfer (HAT) based methods or on single 
electron transfer (SET) based methods. The HAT-based methods measure the ability of an antioxidant to quench free radicals by hydrogen donation. These methods are $\mathrm{pH}$ independent and are usually quite rapid, typically completed in seconds to minutes. One example is the ORAC assay. The SET-based methods detect the ability of a potential antioxidant to transfer one electron to reduce any compound, including metals, carbonyls, and radicals. They are $\mathrm{pH}$ dependent and based on percent decrease in product rather than kinetics, being usually slower than the HAT-based methods [6]. Ferric reducing ability of plasma (FRAP), CUPRAC and TEAC assays are based on SET reaction mechanisms $[14,15]$.

\section{Main advantages and limitations of TAC assays}

One major advantage of TAC assays is that, by definition, estimate the antioxidant components of a sample in a global way. Measuring each antioxidant component individually is labor-intensive and time-consuming, requiring complex and costly techniques [9]. Other advantages of using TAC assays include simplicity of the techniques, low cost per sample, speed of reactions and possibility to be performed using automated, semiautomated, or manual methods $[3,6]$.

However, measurement of only TAC can provide limited information about the antioxidant status, because TAC assays do not measure all antioxidant components. For example, they do not evaluate the role of important enzymes such as superoxide dismutase, glutathione peroxidase, and catalases $[6,16,17]$. Therefore, plasma antioxidant capacity provides a reductionist modelling of an in vivo situation, and, therefore caution is needed in the interpretation of results [18].

\section{What is the best assay for TAC measurements?}

Despite spectrophotometric measurements of TAC are easy and fast, the answer about what would the ideal assay for TAC measurement is controversial due to inherent limitations of each method and because each method measures different TAC components [19]. This situation could explain the variability in results found with different TAC assays. Cao and Prior [20] found no correlation between ORAC and TEAC or between FRAP and TEAC in serum of healthy humans. This agrees with other reports indicating that different results can be obtained when different assays to measure TAC are applied to human serum or plasma $[21,22]$. When dogs with cardiac disorders (mitral endocardiosis and dilated cardiomyopathy) where compared with healthy dogs, no significant differences were found in serum TEAC, but lower values were found in diseased dogs when FRAP was used [23]. In accordance with Huang et al. [24], the major problem is the lack of a method that can measure in an accurate way the global antioxidant capacity of biological samples.

\section{Current situation and objective of the review}

There are a number of reviews regarding the measurement of TAC in foods and biological fluids from humans presenting detailed description of the assay procedures, reaction kinetics, and also advantages and limitations of the different methods [6, 24-29]. This paper studies the spectrophotometric assays which currently are most frequently used to measure TAC in serum samples (TEAC, FRAP and CUPRAC) with a special interest in dogs, and also provides selected information about reports in human medicine for comparative purposes.

It is expected that the information provided here can contribute to increase the use of TAC measurements, especially in companion animal's research and therefore more information could be provided in the future about the behavior of different assays in selected diseases and their clinical use.

\section{TEAC assay}

Trolox equivalent antioxidant capacity (TEAC) assay is generally based on the ability of antioxidants presenting in a sample in reduce or inhibit oxidized products generated in the assay. It is based on the principle that when ABTS (2,2'-azino-bis(3-ethylbenz-thiazoline-6-sulfonic acid) is incubated with a proper chemical, an ABTS radical $\left(\mathrm{ABTS}^{*+}\right)$ is formed. The $\mathrm{ABTS}^{*+}$ has a blue-green color, with maximum absorptions at 650, 734 and $820 \mathrm{~nm}$. Antioxidants in the sample reduce ABTS ${ }^{\circ+}$ suppressing this color production to a degree that is proportional to their concentrations [8]. In human plasma, TEAC measures mainly albumin (that represents 43$53 \%$ of the total value) and uric acid (representing $33 \%)$. In addition, it measures ascorbic acid, $\alpha$ tocopherol, and bilirubin $[8,9]$.

Reaction rate is commonly calibrated with Trolox, a water soluble analogue of vitamin $\mathrm{E}$, and assay results are expressed in mmol Trolox equivalent/L [8]. This method is suitable for automation permitting rapid throughput of samples and various kits based on this method are commercially available.

\section{TEAC versions}

There are different versions of TEAC assay, with variations in how the oxidized radical is generated and times of reaction used [30]. The method of Miller et al. [8] uses metmyoglobin, Arnao et al. [30-32] developed a method for foods and plant material using the horseradish peroxidase enzyme (HRP), Re et al. [10] used potassium persulfate, and Erel [9] used 
$\mathrm{H}_{2} \mathrm{O}_{2}$ in acid medium for producing the oxidized radical.

The Fig. 1 summarizes the principal variations of the TEAC method that have been described.

\section{Advantages and limitations}

The TEAC presents some advantages $[8,9,14]$ :

- operational simplicity

- the radical ABTS is soluble in both aqueous and organic solvent media enabling the simultaneous determination of hydrophilic and lipophilic antioxidants

- can be automated

On the other hand, it also presents limitations such as $[15,16]$ :

- the radical ABTS used in the method does not represent a physiological radical source

- may take a long time to reach an endpoint.

\section{Validation data}

According to the reported validation data, presented in Table 1, TEAC assays described to determine the TAC in sample of human and dogs have good reproducibility.

\section{Studies in human}

In studies made with commercial kits based on the method of Miller et al., Glantzounis et al. [34] and Zulfikaroglu et al. [35] observed significant decreased TAC values in human patients submitted to laparoscopic cholecystectomy. Patients with metabolic syndrome [36] and with prediabetes [37] showed TAC values significantly lower than healthy subjects. In addition, nonsurviving septic patients had higher serum TAC levels than surviving ones [38].
Using the method developed by Erel, Koksal and Kurban [39] reported no significant changes in the serum TAC from human patients before and after abdominal wall hernias resolution. However, significant differences in the values between the surgical techniques used for the hernias resolution were observed. Helicobacter pylori infection produced a decrease in TAC values [40]. In other studies there was no difference in TAC values in patients suffering from brucellosis [41], but TAC was increased in patients with acute appendicitis [42].

\section{Studies in dogs}

Results of studies that determined the TAC by the TEAC methods in serum samples of dogs are shown in Table 2. In this table, it can be observed that TAC determined with the method developed by Erel decreased after surgery, anesthesia, in visceral leishmaniosis, and after vaccination against canine monocytic ehrlichiosis; and increased in demodicosis and parvoviral enteritis. When the method described by Miller et al. was used, dogs with Babesia vogeli, atopic dermatitis and heart diseases showed no significant differences when compared with healthy ones.

\section{FRAP assay}

Ferric reducing ability of plasma (FRAP) assay is based on the principle of reduction of ferrictripyridyltriazine $\left(\mathrm{Fe}^{3+}{ }_{-} \mathrm{TPTZ}\right)$ complex to ferrous tripyridyltriazine $\left(\mathrm{Fe}^{2+}-\mathrm{TPTZ}\right)$ by the antioxidants of a sample at low $\mathrm{pH}$ [12]. The end product $\left(\mathrm{Fe}^{2+}-\mathrm{TPTZ}\right)$ has blue color with absorption maximum at $593 \mathrm{~nm}$ and the change in absorbance is related to the antioxidant capacity of the plasma (Fig. 2).

Uric acid is the main component (can reach up to $60 \%)$ of FRAP in human plasma. In addition, this assay measures ascorbic acid, bilirubin, and $\alpha$ tocopherol [12].

$$
\begin{array}{ll}
- & \text { Enzymes }\left\{\begin{array}{l}
\text { Metmyoglobin [8] } \\
\text { HRP [30] }
\end{array}\right. \\
\text { ABTS }+\mathrm{H}_{2} \mathrm{O}_{2} \stackrel{-}{ } & \text { Potassium persulfate [10] } \\
\text { Acidic pH [9] } & \mathrm{ABTS}^{\bullet+}+\mathrm{H}_{2} \mathrm{O} \text { (blue-green color) } \\
\text { Loss of } \\
\text { color }
\end{array}
$$

Fig. 1 Mainly differences in ABTS ${ }^{*+}$ generation between the different TEAC assays 
Table 1 Coefficient of variation (CV) of the TEAC assay and variants

\begin{tabular}{lllll}
\hline Method & Specie & $\begin{array}{l}\text { Intra-assay } \\
\mathrm{CV}(\%)\end{array}$ & $\begin{array}{l}\text { Inter-assay } \\
\mathrm{CV}(\%)\end{array}$ & Reference \\
\hline $\begin{array}{l}\text { ABTS, metmyoglobin } \\
\text { and } \mathrm{H}_{2} \mathrm{O}_{2}\end{array}$ & Human & $0.54-1.59$ & $3.6-6.1$ & {$[8]$} \\
Kit - Miller et al. [8] & Human & 2.5 & 5.0 & {$[20]$} \\
ABTS and $\mathrm{H}_{2} \mathrm{O}_{2}$ & Human & $1.3-2.5$ & $1.5-2.9$ & {$[9]$} \\
Kit - Erel [9] & Human & No reported & 8.9 & {$[21]$} \\
Kit - Miller et al. [8] & Dogs & 2.8 & No reported & {$[33]$} \\
\hline
\end{tabular}

TEAC, Trolox equivalent antioxidant capacity; ABTS, 2,2'- azino - bis(3 - ethylbenz thiazoline - 6 - sulfonic acid); $\mathrm{H}_{2} \mathrm{O}_{2}$, hydrogen peroxide

For calibration, aqueous solutions of known $\mathrm{Fe}$ $\left(\mathrm{FeSO}_{4 .} 7 \mathrm{H}_{2} \mathrm{O}\right)$ concentration in the range of 100 to $1000 \mu \mathrm{mol} / \mathrm{L}$ are used, and the values are expressed as $\mu \mathrm{mol} / \mathrm{L} \mathrm{Fe}^{2+}$ [12]. This assay can be performed using automated, semi-automated, or manual methods [12, 52].

\section{Advantages and limitations}

The FRAP assay has some advantages [12, 52]:

- no need of highly specialized equipment or skills, or strict control of timing and reaction conditions

- quick and simple to perform and can be easily automated

- reagents are inexpensive and sample pre-treatment is not required

- highly reproducible over a wide concentration range

Table 2 Studies determining the TAC using the various TEAC methods in serum samples of dogs

\begin{tabular}{|c|c|c|c|}
\hline $\begin{array}{l}\text { Disease/effect } \\
\text { studied }\end{array}$ & Method & $\begin{array}{l}\text { Comparison with } \\
\text { healthy animals }\end{array}$ & Reference \\
\hline $\begin{array}{l}\text { Established range in } \\
\text { healthy beagle }\end{array}$ & Kit - Miller et al. [8] & - & [33] \\
\hline Babesia vogeli & Kit - Miller et al. [8] & No difference & [43] \\
\hline Atopic dermatitis & Kit - Miller et al. [8] & No difference & {$[44]$} \\
\hline Heart diseases & Miller et al. [8] & No difference & [23] \\
\hline Parvoviral enteritis & Erel [9] & Increased & {$[45]$} \\
\hline Demodicosis & Erel [9] & Increased & {$[46]$} \\
\hline Visceral leishmaniosis & Erel [9] & Decreased & {$[47]$} \\
\hline After surgery & Erel [9] & Decreased & {$[48]$} \\
\hline $\begin{array}{l}\text { After anaesthetized } \\
\text { with isoflurane }\end{array}$ & Erel [9] & Decreased & {$[49]$} \\
\hline Sarcoptic mange & Erel [9] & No difference & {$[50]$} \\
\hline $\begin{array}{l}\text { After vaccination } \\
\text { against canine } \\
\text { monocytic erlichiosis }\end{array}$ & Erel [9] & Decreased & [51] \\
\hline
\end{tabular}

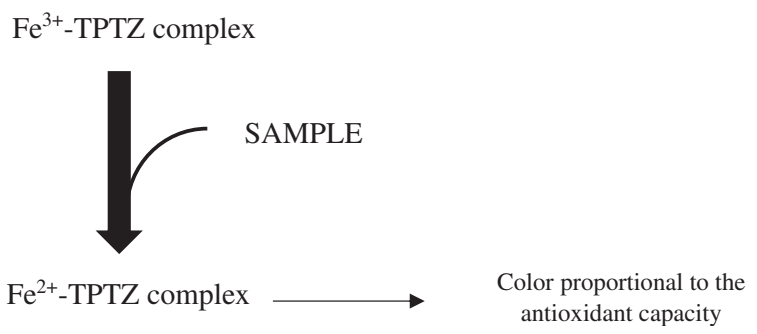

Fig. 2 An overview of FRAP reaction

However, FRAP reaction conditions are far from physiological to measure the TAC (i.e. to maintain iron solubility requires an acidic $\mathrm{pH}$ (3.6)) [26]. In addition, it does not measure the antioxidants containing thiol groups and only measures the reducing capability based upon the ferric ion, which is described by some authors not being relevant to antioxidant activity $[7,29]$.

\section{Validation data}

Few data are published on the FRAP assay validation, being based on studies with human samples. Benzie and Strain [12] reported an intra- and inter-assay CV of $<1.0 \%$ and $<3.0 \%$, respectively; and a recovery of 91-112\%. Jansen and Ruskovska [21] indicated an inter-assay CV of $11.4 \%$.

\section{Studies in human}

Jansen and Ruskovska [21] observed a significant correlation between the TAC values measured by FRAP assay and the TEAC assay developed by Miller et al. in healthy males. Jansen et al. [53] and Haldar et al. [54] observed no differences in the FRAP values when compared smokers with no-smokers, and omnivores with vegetarians, respectively. There was no difference in serum concentrations of FRAP in patients with oral carcinoma before and after the treatment [55]. Hyperglycemia leads to lower FRAP values when compared to healthy subjects [56] and elderly physically disabled patients had lower FRAP values when compared to healthy ones [57].

\section{Studies in dogs}

There is no influence of age on FRAP as older dogs have similar FRAP values than the young ones [58].

Serum FRAP was significantly higher in dogs with heart disease than in control animals [23]. In addition, obese dogs submitted to a weight loss program had higher FRAP values when compared to the baseline [59]; however, the values were not different between healthy dogs and dogs submitted to a weight gain program [60]. 
Dogs with mammary carcinoma of low-grade malignancy had higher FRAP levels when compared with dogs with high-grade mammary carcinoma and healthy dogs [61]. However, no difference in the FRAP levels were observed between dogs with lymphomas and healthy dogs [62].

FRAP increased in plasma of dogs exposed to one therapeutic dose of asoxime chloride, an oxime reactivator used for counteracting intoxication by nerve agents [63] and after supplementation with antioxidant blend [64]. Dogs that received lidocaine or placebo during ovariohysterectomy had no different FRAP values between the treatments and the different times of sampling (before premedication, during suturing, after extubation and after surgery) [65].

\section{CUPRAC assay}

This assay evaluates the capacity of the antioxidants of a sample to reduce the $\mathrm{Cu}^{2+}$ to $\mathrm{Cu}^{1+}$ in the presence of a chelating agent as summarized in Fig. 3. These chelators form colored stable complexes with $\mathrm{Cu}^{1+}$ that have a maximum absorption at 450-490 $\mathrm{nm}$ [13].

The CUPRAC assay measures the thiol-group antioxidants and other plasma antioxidants such as ascorbic acid, $\alpha$-tocopherol, $\beta$-carotene, uric acid, albumin, and bilirubin [13].

\section{CUPRAC versions}

The CUPRAC assays differ mainly in the chelating agent used, that can be bathocuproine (BC), bathocuproinedisulfonic acid disodium salt (BCS), or neocuproine (Nc). An assay based on the $\mathrm{Cu}^{2+}$ reduction using $\mathrm{BC}$ is commercially available [66].

\section{Advantages and limitations}

The method presents some advantages [13, 67]:

- color development is relatively fast

- reagents are relatively stable, cheap, and accessible

- suitable for automation, does not require great expertise or the use of expensive equipment

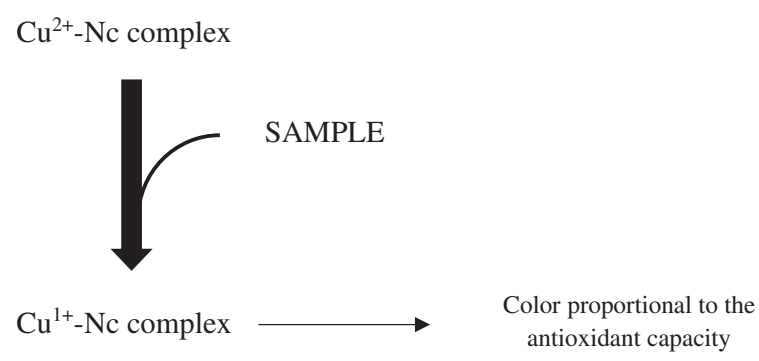

Fig. 3 An overview of CUPRAC reaction
- the redox reaction producing colored species is carried out at $\mathrm{pH} 7$ buffer (close to that of physiological $\mathrm{pH}$ )

- thiols are detected

- can simultaneously measure lipophilic and hydrophilic antioxidants.

On the other hand, the assay does not measure antioxidant enzymes and depending on the CUPRAC version, it can require longer times of measurement and previous sample preparation [13].

\section{Validation data}

The intra- and inter-assay CVs of the CUPRAC method using Nc for human serum were 0.7 and $1.5 \%$, respectively [13], and using BCS were between 0.9 and $5.6 \%$, respectively $[67,68]$. In serum of dogs, the intra- and inter-assay of the CUPRAC method using BCS were between 2 and $9 \%$, respectively [69].

\section{Studies in human}

Cupric ion reducing antioxidant capacity (CUPRAC) was significantly correlated with the FRAP and TEAC in healthy subjects [67]. Gosmaro et al. [68] observed lower CUPRAC values in patients after hemo-dialysis treatment.

\section{Studies in dogs}

Significant lower CUPRAC values were found in serum of dogs with inflammatory bowel disease when compared to healthy dogs [69].

\section{Conclusion}

In this review, we have analyzed the main assays for TAC measurements with special emphasis on their advantages and disadvantages, and the studies where they have been applied in dogs and humans. Based on this analysis, it could be recommended that, if possible, until an ideal reference method is found, various different assays integrated in a panel should be used for TAC evaluation. This recommendation is supported by the fact that depending on the assay performed, the result of TAC could be markedly different. In addition, the combination of TAC assays with more specific analysis of individual antioxidants would provide a wider picture of the antioxidant status.

\section{Abbreviations}

ABTS, 2,2'- azino - bis(3 - ethylbenz - thiazoline - 6 - sulfonic acid); ABTS ${ }^{\cdot+}$ 2,2'- azino - bis(3 - ethylbenz - thiazoline - 6 - sulfonic acid) radical; BC, bathocuproine; BCS, bathocuproinedisulfonic acid disodium salt; CUPRAC, cupric reducing antioxidant capacity; CV, coefficient of variation; DNA: deoxyribonucleic acid; $\mathrm{Fe}^{2+}$-TPTZ, ferrous tripyridyltriazine; $\mathrm{Fe}^{3+}$-TPTZ, ferrictripyridyltriazine; FRAP, ferric reducing ability of plasma; GSH, reduced glutathione; $\mathrm{H}_{2} \mathrm{O}_{2}$, hydrogen peroxide; HAT, hydrogen atom transfer; HRP, 
horseradish peroxidase enzyme; Nc, neocuproine; ORAC, oxygen radical absorbance capacity; SET, single electron transfer; TAC, total antioxidant capacity; TEAC, Trolox equivalent antioxidant capacity

\section{Acknowledgements}

Not applicable.

\section{Funding}

The National Council for Scientific and Technological development (CNPq) of Brazil funded the PhD scholarship of CPR. The Ministerio de Economia y Competitividad of Spain funded AT through a postdoctoral grant (Juan de la Cierva). Seneca Foundation of Murcia Region (19894/GERM/15) also funded this study.

\section{Availability of data and material}

Not applicable.

\section{Authors' contributions}

All listed authors contributed equally to the preparation and writing of the review. In addition, they read and approved the review prior to submission.

\section{Competing interests}

The authors declare that they have no financial or personal relationship(s) which may have inappropriately influenced them in writing this article.

\section{Consent for publication}

Not applicable.

\section{Ethics approval and consent to participate}

Not applicable.

\section{Author details}

${ }^{1}$ Interdisciplinary Laboratory of Clinical Analysis Interlab-UMU, Faculty of Veterinary Medicine, Regional Campus of International Excellence 'Campus Mare Nostrum', University of Murcia, 30100 Espinardo, Murcia, Spain. ${ }^{2}$ Department of Plant Biology (Plant Physiology), Faculty of Biology, University of Murcia, Murcia, Spain. ${ }^{3}$ Department of Animal Medicine and Surgery, Veterinary School, University Autonoma of Barcelona, Barcelona, Spain.

\section{Received: 28 January 2016 Accepted: 3 August 2016}

\section{Published online: 15 August 2016}

\section{References}

1. Rice-Evans CA, Diplock AT, Symons MC. Techniques in Free Radical Research, Laboratory Techniques in Biochemistry and Molecular Biology. London: Elsevier; 1991. Volume 22.

2. Halliwell B. Antioxidants: the basics - what they are and how to evaluate them. Adv Pharmacol. 1996;38:3-20.

3. Marques SS, Magalhães LM, Tóth IV, Segundo MA. Insights on antioxidant assays for biological samples based on the reduction of copper complexesthe importance of analytical conditions. Int J Mol Sci. 2014;15:11387-402.

4. Ghiselli A, Serafini M, Natella F, Scaccini C. Total antioxidant capacity as a tool to assess redox status: critical view and experimental data. Free Radic Biol Med. 2000;29:1106-14.

5. Kohen R, Nyska A. Oxidation of biological systems: oxidative stress phenomena, antioxidants, redox reactions, and methods for their quantification. Toxicol Pathol. 2002;30:620-50.

6. Bartosz G. Non-enzymatic antioxidant capacity assays: Limitations of use in biomedicine. Free Radic Res. 2010;44:711-20.

7. Pinchuk I, Shoval H, Dotan Y, Lichtenberg D. Evaluation of antioxidants: scope, limitations and relevance of assays. Chem Phys Lipids. 2012;165:638-47.

8. Miller NJ, Rice-Evans C, Davies MJ, Gopinathan V, Milner A. A novel method for measuring antioxidant capacity and its application to monitoring the antioxidant status in premature neonates. Clin Sci. 1993;84:407-12.

9. Erel O. A novel automated direct measurement method for total antioxidant capacity using a new generation, more stable ABTS radical cation. Clin Biochem. 2004:37:277-85.

10. Re R, Pellegrini N, Proteggente A, Pannala A, Yang M, Rice-Evans C. Antioxidant activity applying an improved ABTS radical cation decolorization assay. Free Radic Biol Med. 1999;26:1231-7.
11. Cao G, Alessio HM, Cutler RG. Oxygen-radical absorbance capacity assay for antioxidants. Free Radic Biol Med. 1993;14:303-11.

12. Benzie IF, Strain JJ. The ferric reducing ability of plasma (FRAP) as a measure of "antioxidant power": the FRAP assay. Anal Biochem. 1996;239:70-6.

13. Apak R, Güçlü K, Ozyürek M, Karademir SE, Altun M. Total antioxidant capacity assay of human serum using copper (II)-neocuproine as chromogenic oxidant: the CUPRAC method. Free Radic Res. 2005;39:949-61.

14. Prior RL, Wu X, Schaich K. Standardized methods for the determination of antioxidant capacity and phenolics in foods and dietary supplements. J Agric Food Chem. 2005;53:4290-302.

15. Badarinath AV, Rao KM, Chetty CMS, Ramkanth S, Rajan TVS, Gnanaprakash K. A review on in-vitro antioxidant methods: comparisions, correlations and considerations. Int J Pharm Tech Res. 2010:2:1276-85.

16. Sies H. Total Antioxidant Capacity: Appraisal of a Concept. J Nutr. 2007:137:1493-5.

17. Fraga CG, Oteiza PI, Galleano M. In vitro measurements and interpretation of total antioxidant capacity. Biochim Biophys Acta - Gen Subj. 1840;2014:931-4.

18. Costantini D. On the measurement of circulating antioxidant capacity and the nightmare of uric acid. Methods Ecol Evol. 2011;2:321-5.

19. Winter JL, Barber LG, Freeman L, Griessmayr PC, Milbury PE, Blumberg JB. Antioxidant status and biomarkers of oxidative stress in dogs with lymphoma. J Vet Intern Med. 2009;23:311-6.

20. Cao G, Prior RL. Comparison of different analytical methods for assessing total antioxidant capacity of human serum. Clin Chem. 1998;44(6):1309-15.

21. Jansen EH, Ruskovska T. Comparative analysis of serum (anti)oxidative status parameters in healthy persons. Int J Mol Sci. 2013;14:6106-15.

22. Janaszewska A, Bartosz G. Assay of total antioxidant capacity: comparison of four methods as applied to human blood plasma. Scand J Clin Lab Inv. 2002:62:231-6.

23. Hetyey CS, Manczur F, Dudás-Györki Z, Reiczigel J, Ribiczey P, Vajdovich P, Vörös K. Plasma antioxidant capacity in dogs with naturally occurring heart diseases. J Vet Med A Physiol Pathol Clin Med. 2007:54:36-9.

24. Huang D, Ou B, Prior RL. The chemistry behind antioxidant capacity assays. J Agric Food Chem. 2005;53:1841-56.

25. Niki E. Assessment of antioxidant capacity in vitro and in vivo. Free Radic Biol Med. 2010;49:503-15.

26. López-Alarcón C, Denicola A. Evaluating the antioxidant capacity of natural products: A review on chemical and cellular-based assays. Anal Chim Acta. 2013;763:1-10.

27. Amorati $R$, Valgimigli L. Advantages and limitations of common testing methods for antioxidants. Free Radic Res. 2015:49:633-49.

28. Takashima M, Horie M, Shichiri M, Hagihara Y, Yoshida Y, Niki E. Assessment of antioxidant capacity for scavenging free radicals in vitro: a rational basis and practical application. Free Radic Biol Med. 2012;52:1242-52.

29. Prior RL, Cao G. In vivo total antioxidant capacity: comparison of different analytical methods. Free Radic Biol Med. 1999;27:1173-81.

30. Arnao MB, Cano A, Hernandez-Ruiz J, Garcia-Canovas F, Acosta M. Inhibition by L-ascorbic acid and other antioxidants of the 2,2'-azinobis(3-ethylbenzthiazoline-6-sulfonic acid) oxidation catalyzed by peroxidase: A new approach for determining total antioxidant status of foods. Anal Biochem. 1996;236:255-61.

31. Arnao M, Cano A, Acosta M. Methods to measure the antioxidant activity in plant material. A comparative discussion. Free Radic Res. 1999;31:89-96.

32. Arnao MB, Cano A, Acosta M. The hydrophilic and lipophilic contribution to total antioxidant activity. Food Chem. 2001;73:239-44.

33. Nemec A, Drobnič-Košorok M, Skitek M, Pavlica Z, Galac S, Butinar J. Total Antioxidant Capacity (TAC) Values and Their Correlation with Individual Antioxidants in Healthy Beagles. Acta Vet Brno. 2000;69:297-303.

34. Glantzounis GK, Tselepis AD, Tambaki AP, Trikalinos TA, Manataki AD, Galaris DA, Tsimoyiannis EC, Kappas AM. Laparoscopic surgery-induced changes in oxidative stress markers in human plasma. Surg Endosc. 2001;15:1315-9

35. Zulfikaroglu B, Koc M, Soran A, Isman FK, Cinel I. Evaluation of oxidative stress in laparoscopic cholecystectomy. Surg Today. 2002;32:869-74.

36. Hopps E, Canino B, Montana M, Lo Presti R, Averna MR, Caimi G. Behavior of the total antioxidant status in a group of subjects with metabolic syndrome. Diabetes Metab Syndr. 2014:8:166-9.

37. Mohieldein AH, Hasan M, Al-Harbi KK, Alodailah SS, Azahrani RM, Al-Mushawwah SA. Dyslipidemia and reduced total antioxidant status in young adult Saudis with prediabetes. Diabetes Metab Syndr. 2015;9:287-91. 
38. Lorente L, Martín MM, Almeida T, Abreu-González P, Ferreres J, Solé-Violán J, Labarta L, Díaz C, Jiménez A. Association between serum total antioxidant capacity and mortality in severe septic patients. J Crit Care. 2015;30:217. e7-12.

39. Koksal H, Kurban S. Total oxidant status, total antioxidant status, and paraoxonase and arylesterase activities during laparoscopic cholecystectomy. Clin. 2010;65:285-90.

40. Aslan M, Nazligul Y, Horoz M, Bolukbas C, Bolukbas FF, Aksoy N, Celik H, Erel O. Serum prolidase activity and oxidative status in Helicobacter pylori infection. Clin Biochem. 2007;40:37-40.

41. Usta M, Aras Z, Tas A. Oxidant and antioxidant parameters in patients with Brucella canis. Clin Biochem. 2012;45:366-7.

42. Köksal H, Kurban S, Doğru O. Total oxidant status, total antioxidant status, and paraoxonase activity in acute appendicitis. Ulus Travma Acil Cerrahi Derg. 2015;21:139-42.

43. Ciftci G, Ural K, Aysul N, Cenesiz S, Guzel M, Pekmezci D, Sogut Mü. Investigation of the 8-hydroxy-2'-deoxyguanosine, total antioxidant and nitric oxide levels of serum in dogs infected with Babesia vogeli. Vet Parasitol. 2014;204:388-91.

44. Kapun AP, Salobir J, Levart A, Kotnik T, Svete AN. Oxidative stress markers in canine atopic dermatitis. Res Vet Sci. 2012;92:469-70.

45. Kocaturk M, Tvarijonaviciute A, Martinez-Subiela S, Tecles F, Eralp O, Yilmaz Z Ceron JJ. Inflammatory and oxidative biomarkers of disease severity in dogs with parvoviral enteritis. J Small Anim Pract. 2015;56:119-24

46. Martínez-Subiela S, Bernal LJ, Tvarijonaviciute A, Garcia-Martinez JD, Tecles F, Cerón JJ. Canine demodicosis: the relationship between response to treatment of generalised disease and markers for inflammation and oxidative status. Vet Dermatol. 2014;25:72-e24

47. Almeida BFM, Narciso LG, Melo LM, Preve PP, Bosco AM, Lima VMF, Ciarlini PC. Leishmaniasis causes oxidative stress and alteration of oxidative metabolism and viability of neutrophils in dogs. Vet J. 2013;198:599-605.

48. Lee JY, Kim MC. Comparison of Oxidative Stress Status in Dogs Undergoing Laparoscopic and Open Ovariectomy. J Vet Med Sci. 2014;76:273-6.

49. Lee JY. Evaluation of the total oxidant and antioxidant status of the plasma of dogs anaesthetised with isoflurane. Vet Rec. 2013;173:96.

50. Camkerten I, Sahin T, Borazan G, Gokcen A, Erel O, Das A. Evaluation of blood oxidant/antioxidant balance in dogs with sarcoptic mange. Vet Parasitol. 2009;161:106-9.

51. Rudoler N, Harrus S, Martinez-Subiela S, Tvarijonaviciute A, van Straten M, Cerón JJ, Baneth G. Comparison of the acute phase protein and antioxidant responses in dogs vaccinated against canine monocytic ehrlichiosis and naive-challenged dogs. Parasit Vectors. 2015;8:175.

52. Benzie IFF, Strain JJ. Ferric reducing (antioxidant) power as a measure of antioxidant capacity: the FRAP assay. Methods Enzym. 1999;299:15-36.

53. Jansen $E$, Beekhof $P$, Ruskovska T. The effect of smoking on biomarkers of (anti) oxidant status. J Mol Biomark Diagn. 2014;54:583-94.

54. Haldar S, Rowland IR, Barnett YA, Bradbury I, Robson PJ, Powell J, Fletcher J. Influence of habitual diet on antioxidant status: a study in a population of vegetarians and omnivores. Eur J Clin Nutr. 2007;61:1011-22.

55. Shetty KR, Kali A, Shetty KR. Serum total antioxidant capacity in oral carcinoma patients. Pharmacognosy Res. 2015;7:184-7.

56. Padhy R, Acharya SS, Devi N, Swain S, Rattan R. Association of nitrosative and oxidative stress in young type 2 diabetic patients. Int J Res Med Sci. 2015;3:2694-7.

57. Younesi S, Parsian H, Hosseini SR, Noreddini H, Mosapour A, Bijani A, Halalkhor S. Dyshomeostasis of serum oxidant/antioxidant status and copper, zinc, and selenium levels in elderly physically disabled persons: an AHAP-Based Study. Biol Trace Elem Res. 2015;166:136-41.

58. Blount DG, Heaton PR, Pritchard DI. Changes to levels of DNA damage and apoptotic resistance in peripheral blood mononuclear cells and plasma antioxidant potential with age in Labrador Retriever dogs. J Nutr. 2004;134:2120S-2123.

59. Bastien BC, Patil A, Satyaraj E. The impact of weight loss on circulating cytokines in Beagle dogs. Vet Immunol Immunopathol. 2015;163:174-82

60. Van de Velde H, Janssens GPJ, Stuyven E, Cox E, Buyse J, Hesta M. Shortterm increase of body weight triggers immunological variables in dogs. Vet Immunol Immunopathol. 2012;145:431-7.

61. Machado VS, Crivellenti LZ, Bottari NB, Tonin AA, Pelinson LP, BorinCrivellenti S, Santana AE, Torbitz VD, Moresco RN, Duarte T, Duarte MMMF, Schetinger MRC, Morsch VM, Jaques JA, Tinucci-Costa M, Da Silva AS. Oxidative stress and inflammatory response biomarkers in dogs with mammary carcinoma. Pathol Res Pract. 2015;211:677-81.
62. Vajdovich P, Kriska T, Mézes M, Szabó PR, Balogh N, Bánfi A, Arany-Tóth A, Gaál T, Jakus J. Redox status of dogs with non-hodgkin lymphomas. An ESR study. Cancer Lett. 2005;224:339-46.

63. Pohanka M, Novotny L, Zdarova-Karasova J, Bandouchova H, Zemek F, Hrabinova M, Misik J, Kuca K, Bajgar J, Zitka O, Cernei N, Kizek R, Pikula J. Asoxime (HI-6) impact on dogs after one and tenfold therapeutic doses: assessment of adverse effects, distribution, and oxidative stress. Environ Toxicol Pharmacol. 2011;32:75-81.

64. Heaton PR, Reed CF, Mann SJ, Ransley R, Stevenson J, Charlton CJ, Smith BHE, Harper EJ, Rawlings JM. Role of dietary antioxidants to protect against DNA damage in adult dogs. J Nutr. 2002;132:1720S-1724.

65. Mesgarani $H$, kalahroodi hossein, Emami M, Heidarpour M: Evaluation of a constant rate of lidocaine on oxidative stress parametere in dogs undergoing ovariohystrectomy. 4th International Symposium of Veterinary Surgery 2014.

66. Da Cruz G: Use of bathocuproine for the evaluation of the antioxidant power in liquids and solutions. 2003

67. Campos C, Guzmán R, López-Fernández E, Casado Á. Evaluation of the copper(II) reduction assay using bathocuproinedisulfonic acid disodium salt for the total antioxidant capacity assessment: The CUPRAC-BCS assay. Anal Biochem. 2009;392:37-44.

68. Gosmaro F, Bagnati M, Berto S, Bellomo G, Prenesti E. Measurement of total antioxidant capacity of human plasma: Setting and validation of the CUPRAC-BCS method on routine apparatus ADVIA 2400. Talanta. 2013;115:526-32.

69. Rubio CP, Tvarijonaviciute A, Martinez-Subiela S, Hernández-Ruiz J, Ceron JJ. Validation of an automated assay for the measurement of cupric reducing antioxidant capacity in serum of dogs. BMC Vet Res. 2016;12:137.

\section{Submit your next manuscript to BioMed Central and we will help you at every step:}

- We accept pre-submission inquiries

- Our selector tool helps you to find the most relevant journal

- We provide round the clock customer support

- Convenient online submission

- Thorough peer review

- Inclusion in PubMed and all major indexing services

- Maximum visibility for your research

Submit your manuscript at www.biomedcentral.com/submit
) Biomed Central 